University of Nebraska - Lincoln

DigitalCommons@University of Nebraska - Lincoln

February 1994

\title{
Socialization of Children's Vicarious Emotional Responding and Prosocial Behavior: Relations With Mothers' Perceptions of Children's Emotional Reactivity
}

\author{
Richard A. Fabes \\ Arizona State University \\ Nancy Eisenberg \\ Arizona State University \\ Mariss Karbon \\ Arizona State University \\ Jane Bernzweig \\ Arizona State University \\ Anna Lee Speer \\ Arizona State University \\ See next page for additional authors \\ Follow this and additional works at: https://digitalcommons.unl.edu/psychfacpub \\ Part of the Psychiatry and Psychology Commons
}

Fabes, Richard A.; Eisenberg, Nancy; Karbon, Mariss; Bernzweig, Jane; Speer, Anna Lee; and Carlo, Gustavo, "Socialization of Children's Vicarious Emotional Responding and Prosocial Behavior: Relations With Mothers' Perceptions of Children's Emotional Reactivity " (1994). Faculty Publications, Department of Psychology. 141.

https://digitalcommons.unl.edu/psychfacpub/141

This Article is brought to you for free and open access by the Psychology, Department of at DigitalCommons@University of Nebraska - Lincoln. It has been accepted for inclusion in Faculty Publications, Department of Psychology by an authorized administrator of DigitalCommons@University of Nebraska - Lincoln. 


\section{Authors}

Richard A. Fabes, Nancy Eisenberg, Mariss Karbon, Jane Bernzweig, Anna Lee Speer, and Gustavo Carlo 


\title{
Socialization of Children's Vicarious Emotional Responding and Prosocial Behavior: Relations With Mothers' Perceptions of Children's Emotional Reactivity
}

\author{
Richard A. Fabes, Nancy Eisenberg, Mariss Karbon, Jane Bernzweig, \\ Anna Lee Speer, and Gustavo Carlo
}

\begin{abstract}
We examined mother-child emotion-related interactions and how these interactions related to mothers' perceptions of children's emotional reactivity. Mothers of 49 kindergartners and 54 2nd graders told their children 2 stories about distressed others. Children's emotional, physiological, and prosocial responses were also obtained. Mothers rated children's tendencies to become emotional when exposed to distressed others. For kindergartners, mothers' perceptions of children's emotional reactivity were positively related to her use of positive facial expressions. Mothers' perceptions of 2nd graders' emotional reactivity were inversely related to maternal responsiveness. For both age groups, children's skin conductance was inversely related to helpfulness. These findings suggest that mothers may "adjust" their interactions with their children based on their perceptions of children's emotional tendencies.
\end{abstract}

Although there has long been an interest in the study of vicarious emotional responses such as empathy (see Wispe, 1987, for a historical review), relatively little is known about the familial factors that influence their development and expression. This is true despite the facts that vicarious emotional responses frequently are considered to play an important role in moral and social behavior (e.g., Ratson, 1987; Hoffman, 1982; Staub, 1989) and that the family often is considered the primary agent for socializing children's emotional responses and responsiveness to others (Barnett, 1987; Halberstadt, 1986). The central purposes of the present study were to examine (a) how mothers' responsiveness to their children in emotion-laden contexts varied with their perceptions of their children's emotional reactivity and (b) how these maternal responses and perceptions influenced children's vicarious emotional responding and prosocial behavior.

When examining factors associated with the development of vicarious emotional responding, one must differentiate among the different emotional responses that frequently have been labeled empathy. Empathy is defined as an emotional reaction that is based on the apprehension of another's emotional state or condition and is identical or similar to the other's emotional state (Eisenberg \& Strayer, 1987). Sympathy is defined as an other-oriented emotional reaction to another's emotional state or condition, whereas personal distress is defined as a self-oriented aversive reaction such as anxiety or discomfort (Batson, 1987). Both sympathy and per- sonal distress may result from empathy; however, sympathy has been positively associated with altruism when it is easy to escape, whereas personal distress has been unrelated or negatively correlated with prosocial behavior in easy escape situations (Batson, 1987; Eisenberg \& Fabes, 1990).

Among the factors that determine whether individuals are prone to sympathy or personal distress may be their dispositional level of emotional reactivity and their ability to regulate emotional arousal and emotion-based actions. Both Hoffman (1982) and Eisenberg and Fabes (1992) have argued that empathic overarousal is experienced as aversive and may result in a focus on the self rather than others. In fact, negative emotional arousal does seem to engender a focus on the self (Wood, Saltzberg, \& Goldsamt, 1990). Thus, it is reasonable to argue that individuals who are unable to maintain their emotional reactions within a tolerable range, and therefore tend to become overaroused, are prone to personal distress and engage in relatively low levels of prosocial behavior.

On the basis of such arguments, Eisenberg and Fabes (1992) have proposed that the ability to regulate emotional arousal and emotion-based behavior facilitates sympathetic responding. Consistent with this view, Rothbart, Ahadi, and Hershey (in press) found that mothers' reports of children's regulation and controlled emotionality (i.e., temperamental inhibitory control, attentional focusing, low intensity pleasure, and perceptual sensitivity) were positively correlated with mothers' reports of their 7-year-olds' empathy. Simi-

Richard A. Fabes and Mariss Karbon, Department of Family Resources and Human Development, Arizona State University; Nancy Eisenberg, Jane Bernzweig, Anna Lee Speer, and Gustavo Carlo, Department of Psychology, Arizona State University.

This research was funded by a grant from the National Science Foundation (BNS-8807784) to Richard A. Fabes and Nancy Eisenberg and by a Research Scientist Development Award from the National Institute of Mental Health (K02 MN00903) to Nancy Eisenberg.

We wish to express our appreciation to the administrators, teachers, students, and parents at Laird, Rover, Evans, and Hudson Elementary Schools for their assistance and participation. We also wish to thank Neil Bechtel, Joseph Campos, and Ernest Lindholm for their advice regarding technical matters, and Debra Troyer, Galen Switzer, Beth Haley, Richard Klein, Qhyrrae Michelieu, Tiffany Beggs, Joe Wright, Lorena Polazzi, and Sandy Burke for their assistance in data collection and coding. 
larly, in a recent study (Eisenberg et al., 1993), adults' dispositional personal distress was associated with individual differences in emotion regulation. Thus, the ability to regulate emotion appears to play a role in vicarious emotional responding. Consequently, socialization practices that foster optimal emotion regulation would be expected to enhance children's sympathy and prosocial behavior.

Although research on the socialization of children's vicarious emotional responding is relatively sparse, it does provide some support for the notion that socialization practices that facilitate children's regulation of emotion are associated with individual differences in children's empathy and sympathy. For example, parental encouragement of sons' (but not daughters') attempts to actively deal with situations that have caused them to experience negative affect has been correlated with boys' sympathy (Eisenberg et al., 1992). Furthermore, among children in mid-elementary school, parental restrictiveness with regard to the display of emotions that are likely to hurt others' feelings has been associated with children's sympathy (Eisenberg, Fabes, Schaller, Carlo, \& Miller, 1991), although such restrictiveness may be associated with distress in younger children (Eisenberg et al., 1992). Thus, parental practices that are associated with the constructive regulation of vicarious emotional arousal may vary with the age and sex of the child.

Parents may also foster children's ability to regulate their emotion in a variety of indirect ways. As one example, Gianino and Tronick (1988) have argued that maternal responsiveness may help children to develop skills for regulating their emotion. Responsive mothers facilitate optimal regulation in their children through interactions that result in shared, positive emotional states. Out of these interactions, children develop a sense of effectance that modifies their subsequent performance In other interactions. Thus, it is logical to argue that mothers who are emotionally available to their children may promote optimal responsiveness to others in their children, whereas "emotionally unavailable" mothers interfere with optimal responsiveness. Consistent with this view, children's empathy or sympathy has been associated with a secure mother-child attachment (Kestenbaum, Farber, \& Sroufe, 1989), parental involvement and satisfaction with the parenting role (Koestner, Franz, \& Weinberger, 1990), empathic and supportive parenting (Barnett, King, Howard, \& Dino, 1980; Zahn-Waxler, Radke-Yarrow, \& King, 1979), and parental empathy (particularly for same-sex children; Eisenberg et al., 1991; Fabes, Eisenberg, \& Miller, 1990). Parental responsiveness to children's distress has also been linked to children's social competence (Roberts \& Strayer, 1987), whereas low parental involvement has been correlated with children's disturbed attachments, impulsivity, and poor emotional control (Egeland \& Sroufe, 1981; Pulkkinen, 1982). Bryant (1987) suggested that responsive, supportive parents facilitate the development of empathy by buffering children's stressful experiences so that the children do not become overly aroused and, consequently, are able to develop the skills necessary for managing situations involving vicariously induced affect.

It is also likely that the relation between parental practices and the development of children's empathy, sympathy, and prosocial behavior is not unidirectional. For example, Eisenberg and Fabes (in press) found that parents' emotion-related practices were influenced by their perceptions of their chil- dren's temperament. Thus, a central focus in the present study was on the relation of child characteristics and parental perceptions of their children to children's sympathy, personal distress, and prosocial behavior. On the basis of the conceptual work of Bell (1968), Bugental and Shennum (1984), and others, we assumed that parental practices are in part a function of children's characteristics and parental perceptions and attributions of those characteristics. Specifically, parents' behaviors in situations involving children's emotion are based not only on their own values and beliefs but also on their children's emotion-related behaviors and parental perceptions of their children's relevant capacities and behaviors. Because children vary in the level of emotional arousal that they can manage effectively, parental behaviors that foster the maintenance of an optimal level of arousal may vary as a function of characteristics of the child. Specifically, it is proposed that parental effects on children's emerging emotions and behaviors when exposed to others in distress are determined by bidirectional influences between children and parents: Children influence parents so that parents alter their behavior and produce a unique socializing environment for each child; in turn, children's behaviors are altered (and so on).

Of particular interest in the present study were the interrelations among mothers' perceptions of their children's emotional reactivity, their behavior with their children in contexts involving potential vicarious emotional arousal, and children's sympathy, personal distress, and prosocial behavior. If a mother believes that her child is easily emotionally distressed, she is likely to act in a manner that is different from mothers who believe that their child is less emotionally reactive. Consistent with this reasoning, several researchers have found that irritable children experience less responsive and less stimulating contact with their mothers (although these findings depend somewhat on the characteristics of the mother and the context; see Crockenberg, 1986, for a review). Mothers of emotionally reactive children may also sometimes refrain from certain types of socialization efforts. Maccoby, Snow, and Jacklin (1984) found that mothers of difficult boys exerted less pressure on these boys than did mothers of less difficult boys. Mothers of difficult boys appeared to be have reacted to their children's emotional reactivity by backing away from some types of socialization efforts.

Unfortunately, there is relatively little research on the relation of children's sympathy and prosocial behavior to either mothers' perceptions of their children or maternal practices that would be expected to foster children's affect regulation. Moreover, the sparse research on the socialization of vicarious emotional responding is limited by the fact that most data on the topic were obtained through interviews and questionnaires completed by parents. In one of the few observational studies involving school-age children, Eisenberg et al. (1992) directly examined mother-child interactions by having them watch a sympathy-inducing videotape together and analyzing their behaviors and interactions. Although Eisenberg et al. (1992) found some significant relations, the context used in their study probably limited the quantity and variety of mother-child interactions because, by its nature, watching TV limits the amount and quality of interactions among viewers (Robinson, 1981). Thus, the database on the socialization of vicarious emotional responsiveness is limited in scope and quantity, 
with very little information derived from direct observations of parent-child interactions dealing with emotions.

In the present study, we obtained direct observations of mother-child interactions regarding emotion-laden topics and a measure of mothers' perceptions of their children's tendencies to become emotionally reactive when exposed to others in distress. Specifically, mothers of kindergarten and secondgrade children were asked to tell their children stories about other children who were experiencing distress. Then, in another context, mothers were presented with hypothetical stories in which their child was exposed to others in distress and asked to indicate the degree to which their children would react emotionally in these situations.

The children of these mothers also watched a film about purportedly real children who had been hurt in an accident. During the time the child watched the stimulus tape, we surreptitiously videotaped his or her facial reactions and monitored the child's physiological responses to the film (e.g., heart rate and skin conductance). Children also were asked to verbally report how they felt during the film. Finally, children were given an opportunity to help children like the ones they saw in the film. Thus, we were able to examine the relations among mother-child interactions, mothers' perceptions of children's emotional reactivity, and children's vicarious responding and prosocial behavior.

On the basis of the previously reviewed research and theory, maternal responsiveness and attention to their children in contexts involving vicarious emotional arousal were expected to be correlated with relatively high levels of children's sympathy and prosocial behavior. However, because of differences among children in their ability to regulate affect, we hypothesized that maternal behaviors would vary as a function of mothers' perceptions of their children's emotional reactivity. For example, mothers of reactive children might be expected to buffer their children's negative affect by heightening their own expression of positive affect or by being particularly responsive and attentive in distressing situations.

Furthermore, mothers' perceptions of, and reactions to, their children's vicarious emotion were expected to vary with the age and sex of their children. To examine age-related changes in the relations between maternal and child variables, we included boys and girls in kindergarten and second grade in this study. Important changes in cognitive as well as environmental factors occur in the early school years (see Higgins \& Parsons, 1983), and these may contribute to developmental differences in children's regulatory control of emotion and emotion-related behavior. For example, it is likely that older children's more sophisticated cognitive abilities and sociocognitive knowledge allow for greater coordination of external and internal stimuli, facilitating older children's emotional regulation (Kopp, 1989; Santostefano, 1985). Moreover, with entry into elementary school, demands for greater control of behavior increase. Children are expected to sit quietly for longer periods of time and to show restraint within the classroom. In addition, second graders' more extensive peer experience may foster their ability to regulate vicarious emotion, because peer experience provides opportunities to learn socially acceptable modes of managing negative affect (Gottman \& Mettetal, 1986). Thus, kindergarten-age children may be entering an important pe- riod in the development of emotional self-regulation during which mothers still perceive the need to be contributing actively to socialization of emotionality and tailoring their behavior to the perceived needs of their children. By second grade, however, mothers may feel their children have developed adequate internal controls and may take less active regulatory steps in interacting with their children.

On the basis of the aforementioned age-related changes, we expected mothers of younger children to be more responsive, attentive, and affectively positive in distressing circumstances than mothers of older children. Furthermore, there is evidence that females are more likely than males to evidence empathy, and sympathy and gender differences in empathyrelated behaviors have been found at early ages (e.g., ZahnWaxler, Robinson, \& Emde, 1992). Moreover, one of the most prevalently held gender stereotypes is that girls are regarded as more emotionally vulnerable than boys (Brody, 1985). Thus, it is not surprising that Block (1979) found that parents tended to be more responsive toward their daughters' emotional reactions, whereas they tended to emphasize the control of emotions for their sons.

On the basis of the age and gender differences described earlier, it is logical to expect that if mothers generally believe or have evidence that girls and younger children are more likely than boys and older children to be emotionally aroused and distressed when exposed to others in distress, they would be expected to act in ways that are likely to lessen the impact of the emotionally charged context (and thus attenuate the likelihood that the child would become overaroused and experience personal distress). Mothers of older children or boys may feel less of a need to directly influence children's affective responding and may rely primarily on providing a supportive environment that maximizes or enhances the boys' or older children's ability to control and regulate their own emotional states.

In the present study, heart rate (HR) and skin conductance (SC) were used as physiological indexes of vicarious responding. Heart-rate deceleration has been found in sympathy-inducing contexts (Craig \& Lowery, 1969; Eisenberg et al., 1988 ) and has been associated with prosocial behavior (Eisenberg et al., 1989; Eisenberg, Fabes, Miller, Shell, \& Plumlee, 1990). In contrast, HR acceleration has been associated with anxiety and active coping (Cacioppo \& Sandman, 1978; Craig, 1968) and low levels of children's helpfulness (Eisenberg \& Fabes, 1990; Eisenberg et al., 1989). Thus, HR deceleration during exposure to a distressed person appears to be a reasonable marker of other-oriented responding and sympathy (Eisenberg et al., 1988), whereas HR acceleration appears to reflect self-focused anxiety and distress.

Skin conductance has been viewed as an indirect marker of intensity of emotional arousal, and researchers have shown that people tend to exhibit SC reactivity when they are fearful or anxious (Craig, 1968; Sparks, 1989). However, there is only limited evidence available that links SC to children's vicarious emotional responding and related behaviors. Because sympathetic feelings typically are less physiologically arousing than are feeling of personal distress (Shaver, Schwartz, Kirson, \& O'Connor, 1987), we expected SC to more likely be a correlate of personal distress than sympathy. Consistent with this argument, Eisenberg et al. (1991) recently found that SC 
reactivity was positively related to girls' facial distress while watching a sympathy-inducing tape and negatively related to dispositional sympathy. In addition, children exhibited more $\mathrm{SC}$ in reaction to a distressing than a sympathy-inducing film. Moreover, Fabes, Eisenberg, and Eisenbud (1993) found that SC reactivity was positively related to girls' (but not boys') reported distress while watching a distressing videotape and inversely related to their helpfulness. On the basis of these limited findings, we expected SC reactivity to be inversely related to indexes of sympathy and helpfulness and positively related to indexes of personal distress. Thus, one additional purpose of this study was to examine further the usefulness of sc as an internal marker of vicarious emotional responding.

\section{Method}

\section{Subjects}

Participants were 49 kindergartners (22 girls and 27 boys; $M$ age $=73.3$ months, $S D=4.01$, range $=67$ to 82 months), 54 second graders (29 girls and 25 boys; $M$ age $=97.8$ months, $S D=4.60$, range $=89$ to 108 months), and their mothers. The children were recruited from schools in middle-class, suburban neighborhoods. Approximately $74 \%$ of the children were White, $8 \%$ were Hispanic, $8 \%$ were American Indian, 7\% were of Asian heritage, and 3\% were Black. Mean years of education for the mothers in this study was $14.18(\mathrm{SD}=2.21$; range $=11$ to 20 years $)$, and the median family income was $\$ 40,000$ (range $=\$ 8,000$ to $\$ 100,000$ ). Three additional children were dropped from the study because they expressed knowledge of the study's purpose or were suspicious about the authenticity of the study. Children and mothers were paid a total of $\$ 10$ for their participation.

\section{Procedure}

Each child and his or her mother came to the university and were met by two experimenters (one was always the same sex as the child and the other was a woman who worked with the mother). After obtaining the necessary permission, the mother and child were told that they would be looking at some story books and then watching some films. The mother and child were then led into an experimental room that contained a couch positioned in front of a television set and videotape recorder.

Mother-child storytelling interaction. After the mother and child were made comfortable, the mother was asked to come out of the room with one of the experimenters. In the hallway, the mother was given general instructions for the stories to be told to the child. Mothers were told that they would be telling the child two stories (one at a time) and that they were to use the story books provided by the experimenter. The two story books contained pictures depicting the story but did not contain any words. The two stories were about children who were experiencing distress. The children in each story were depicted in gender-neutral ways so that we could tell the mother that the main child character in each story was the same sex as that of the child subject.

One story (the accident story) was about a child name Erin (or Aaron) who was shown climbing a tree and falling down and cutting open her (or his) head. The child was clearly in pain and was taken to the doctor's office. In the doctor's office, the child was shown getting stitches and being comforted by the parent. Afterward, the child was depicted telling other children about the accident.

The second story (the pet story) was about a child name Sandy who became sad because his (or her) pet had become sick. After a few pictures, it became clear that Sandy's pet dog had died. Sandy was shown becoming very despondent and his (or her) parents tried to comfort him (or her). At school one day, Sandy became so upset that he (or she) pushed and hurt another student. Sandy's teacher was shown comforting and talking to the hurt student. Sandy was depicted crying and being comforted by a friend. At the end, Sandy was shown happily picking out a new puppy.

The mother was given one of the stories (in a random, counterbalanced order) and, without describing the emotional content of the story, was told the general story portrayed in the picture books. The mother was instructed to tell the story to her child in whatever fashion she desired. She was encouraged to use her own language and to take as long as she wanted. No limits were placed on what or how the mother could tell the story to her child and was told "to feel free to act or talk as you would at home." Finally, the mother was instructed to ring a bell on the side of the couch when she was finished telling the story.

The mother reentered the experimental room, proceeded to tell the story to her child, and rang the bell to notify the experimenter that she was done. The mother-child storytelling interactions were videotaped from behind a one-way mirror. The mothers, but not the children, were aware of the fact that they were being videotaped.

After ringing the bell, the mother went with one of the experimenters and received the same basic instructions for the next story. The mother then entered alone, told the story, and rang the bell after telling the second story. The mother-child interactions were again videotaped.

Child-viewing indexes. After a brief introduction to the physiological equipment, the HR and SC electrodes were attached to the child. The SC electrodes were attached (but not connected to the equipment) between the two stories told by the mothers. The HR electrodes were attached after the stories were told.

For HR, two prejelled electrocardiograph electrodes were placed on the left side of the child - one on the chest below the clavicle near the sternum and one just above the clavicle (further out from the sternum). A third HR electrode served as aground and was placed on the child's back. In addition, two 8-mm silver-silver chloride SC electrodes were attached to the palmar surface of the child's nondominant hand (using a 9\% saline Unibase cream mixture as paste).

After the HR electrodes were attached and both the SC and HR electrodes were connected to the physiological equipment (see later), the child was told that he or she would be watching a film about real boys and girls just like him or her. The experimenter then pointed to a row of videotapes and told the child that there were many different tapes and that each boy and girl who came to the university watched a different film. In reality, all children watched the same film. To determine which film the child was to watch, the experimenter reached into a bowl that contained a large number of folded pieces of paper and pulled one out. The number on the piece of paper indicated the film that the child was to watch; however, all numbers in the bowl were the same. This procedure was designed to foster the belief that the child was the only person who would see that particular tape. Because the helping task was related to this tape, this procedure minimized the likelihood that children would divest responsibility for helping to the larger group (i.e., to think that he or she did not need to help because others would).

The experimenter pulled out that particular tape, put it into the videotape recorder, and told the child to watch the film carefully because he or she was the only one who would be watching that film. After starting the tape, the experimenter told the child to ring the bell when the film was over and then left the room. The child's HR, SC, and facial expressions were recorded during the film.

The stimulus film used in this study was about a family whose children had been injured in an accident (used previously by Eisenberg et al., 1990). In the film, which was approximately 3 min long, a newscaster introduced the notion that accidents happen to children and that he was going to interview a family in which the children had an accident. During the interview, the mother described how her son and daughter, who were approximately the same age as the 
children in the study, accidentally fell from their tree house and hurt themselves when the tree branch broke. The children were bandaged and in casts, and spoke briefly, expressing pain, sadness, boredom, and the desire to go home. The film was preceded by $15 \mathrm{~s}$ of colored bars.

After the child rang the bell to indicate the film had ended, the experimenter returned and asked the child to rate his or her negative emotional reactions to the film. The child was read different emotion adjectives reflecting sympathy (four items: feeling sorry, sad, bad for somebody, arid concerned for others) and distress (three items: feeling nervous, afraid, and uncomfortable) and was asked to indicate how much he or she felt each of these emotions while watching the film. The order of the adjectives was counterbalanced across subjects. These adjectives have been used in prior research and have been found to reliably differentiate sympathetic and distress responses (Datson, Fultz, \& Schoenrade, 1987; Eisenberg et al., 1989; Eisenberg et al., 1991). The child was asked to indicate the degree to which he or she felt each emotion using a 5-point scale (with $1=$ didn't feel that way at all and $5=$ felt that way a whole lot). To help the child understand the scale, we presented the scale visually in the form of five stacks of checkers that differed in height.

The electrode leads were then disconnected and the experimenter told the child that he or she had to go get something that he or she had left in another room. The child was told that while the experimenter was gone, the child could either put crayons in crayon boxes for the children in the tape and other children at the hospital or could play with any of the attractive toys contained in a box brought out by the experimenter (e.g., a computer game, comic books, or coloring pens). The experimenter then showed the child how to put the crayons into the box and told the child to put any finished boxes into a larger box with a lid addressed to the children at the hospital (the box already contained some filled boxes of crayons). The larger box was used so that the child would know that the experimenter could not easily determine how many boxes the child filled. The child was then left alone for $4 \mathrm{~min}$.

During these $4 \mathrm{~min}$, the amount of time (in seconds) that the child spent putting crayons into the boxes was recorded through the one-way mirror. The number of crayons put into the boxes was counted after the session was over.

When the experimenter returned to the room, the crayons and toys were put away and the child was told that the children in the film were okay and were doing better. The child was probed for suspicion regarding their knowledge of the procedures and whether they had any suspicions that the children in the film were actors. The child then received his or her money and was reunited with his or her mother.

Maternal perceptions of children's emotional reactivity. After the second picture story was told, the mother went off with a female experimenter to a different room to complete some questionnaires. As part of a larger study involving the socialization of children's coping (not reported here), mothers were presented with four hypothetical stories in which their children were exposed to other children in distress (e.g., "On your child's way to a friend's house to play, your child sees another child fall off a bike. The child is upset and crying because he/she was hurt and bleeding from the arm," or "One day, your child sees another child who is upset and crying and your child finds out that the other child's pet just died"). Mothers were then asked to indicate how their children would respond in each situation. To obtain a measure of children's emotional reactivity when exposed to others' distress, mothers were asked to indicate on a 1 (not at all likely) to 7 (extremely likely) scale the degree to which their children would become upset or uncomfortable on being exposed to the other child's distress. Mean scores across the four stories were computed and used as an index of children's tendencies to become emotionally reactive when exposed to others in distress. The alpha for the fouritem emotional reactivity index was .74. Data were lost for 1 child because the mother failed to complete this measure.

\section{Data Coding}

Maternal storytelling indexes. The videotaped mother-child story-telling interactions were independently coded by two persons who had no familiarity with the other data in the study. Reliability was assessed by having coders overlap on 32 subjects. Because of equipment problems, mother-child data were lost for 1 mother-child dyad.

For each story, two interaction-related variables were coded (as well as facial reactions; see next two paragraphs). These two variables were selected because they have been empirically and theoretically related to empathic and prosocial responding.

The first variable was maternal warmth. For each story, maternal warmth consisted of a single rating judged on a scale from 1 (very low) to 7 (very high) based on the degree to which the mother interacted, responded, and reacted to her child during the story (e.g., the degree of eye contact made by the mother, the degree to which the mother spoke to the child in a pleasant tone of voice, and the physical proximity and contact between mother and child). Maternal warmth was coded because of the prior findings indicating that if a child has a warm and nurturant caregiver, their emotional needs are likely to be met and their empathic responsiveness is enhanced. If the child's emotional needs are met, this decreases the likelihood that the child will be preoccupied with his or her own distress (Kestenbaum et al., 1989). Pearson correlations between the two coders' judgments of maternal warmth were .80 and $.88, p s<.0001$, for the pet and accident stories, respectively.

The second maternal storytelling variable was maternal attentional directiveness. Attentional directiveness also consisted of a single rating coded on a 1 (very low) to 7 (very high) scale based on the degree to which the mother directed the child's attention to the story material (e.g., pointing to pictures, telling the child to "look at this," or eliciting child involvement or perspective taking by saying, "this is just like what happened to you"). This variable was chosen for inclusion because mothers who foster children's perspective-taking skills likely promote children's consideration of others' needs and their empathic and prosocial responsiveness (see Eisenberg, 1992). Pearson correlations between the two coders' judgments of attentional directiveness for the pet and accident stories for attentional directiveness were .82 and $.89, p \mathrm{~s}<.0001$, respectively. ${ }^{1}$

Maternal facial expressions. Mothers' facial expressions during the storytelling interactions were coded by persons who had no familiarity with the other data in the study (the reliability coder cod-

${ }^{1}$ From the transcripts of the mother-child interactions, we also coded the number of positive and negative emotion words used by the mother when telling the stories $(\kappa=.96)$. According to a 2 (sex) $\times 2$ (grade) repeated measures analysis of covariance (covarying story order) computed for the rate per minute of mothers' use of positive and negative emotion words (computed by dividing the number of positive and negative emotion words used by the number of minutes per story), there was a significant main effect for type of emotion word and an Emotion Word $\times$ Grade interaction, $F \mathrm{~s}(1,97)=$ 41.21 and $3.80, p \mathrm{~s}<.0001$ and .05 , respectively. When telling stories, mothers used negative emotion words at a significantly greater rate than they used positive emotion words $(M \mathrm{~s}=1.09$ and $0.54, S D \mathrm{~s}$ $=0.43$ and 0.81 , respectively). Simple effects analyses revealed that mothers used more emotion words per minute when telling stories to their younger children than they did when telling stories to their older children, $F(1,97)=4.64, p<.05(M \mathrm{~s}=0.69$ and $0.39, S D \mathrm{~s}=1.08$ and 0.26 , respectively). There were no grade effects found for mothers' use of negative emotion words. Moreover, when we computed correlations between mothers' use of emotion words and the other study indexes, the number of relations found was below chance level (in particular, maternal facial expressiveness was not correlated with their use of emotion words). 
ed 35 subjects). The sound was eliminated during coding to keep the coders unaware of what was going on during the interactions.

For every 30 -s period of real time, each type of facial expression was coded on a scale from 1 (no display of emotion) to 5 (strong display of emotion). The coders used this scale to score the degree to which mothers displayed happy, sad, distressed, disgust, and concerned facial expressiveness during each 30 -s period. Sadness, happiness, and disgust were coded with criteria very similar to those of Ekman and Friesen $(1975,1978)$. However, maximum responding during the time period (as well as duration) and specific facial expressions were coded, not specific facial movements. Sadness was coded primarily based on a down-turned mouth and triangulated eyes and brows; however, some sadness was also coded if the child's cheeks were flaccid or droopy. Distressed facial reactions were coded if the mother displayed an expression similar to Ekman and Friesen's mild apprehension (e.g., eyebrow somewhat raised and pulled together) or exhibited nonfunctional nervous mouth and lip movements, such as biting the lips. Concerned attention was coded by using the criteria outlined in Eisenberg et al. (1989) and Eisenberg et al. (1991) and included eyebrows pulled forward over the nose and down, head or body tilted forward, and bottom eyelid slightly raised. Interrater reliability was computed for each emotional expression (Pearson correlations), and these ranged from. 76 to .99 , all $p \mathrm{~s}<.0001$ (mean correlation was .88), and kappa coefficients based on codings of the presence versus absence of a facial expression ranged from .64 to .89 (mean $\kappa=.81)$.

Because each story told by the mother was of a different length, mothers' scores for each emotion were summed together and divided by the number of 30 -s periods to obtain an index of facial expression per 30-s period of storytelling. We then computed a composite index by averaging the scores for each maternal expression across the two stories. Codings of like facial expressions across the two stories were positively correlated; correlations for facial expressions ranged from .47 to .59 , all $p \mathrm{~s}<.0001$ (mean $r=.52$ ).

Facial expressions of disgust and concerned attention occurred infrequently (e.g., across both stories, $M \mathrm{~s}=1.008$ and $1.01, S D \mathrm{~s}=$ 0.03 and 0.02 , respectively; recall that a score of $1.00=$ no display of an emotion). Thus, these expressions were not used. Moreover, the maternal facial expressions of sadness and distress were related, $r(101)=.34, p<.001$. We then created a composite of maternal negative facial expressions by computing the mean of maternal sadness and distress across both stories?

Children's verbal reactions to the film. We computed composite indexes of self-reported negative emotional responses to the film by determining the mean ratings for sympathy and distress adjectives. The alphas for the three-item distress composite and the four-item sympathy composite were .35 and .66 , respectively. Because of the low reliability for the distress index, we do not discuss it further.

Children's negative facial reactions to the film. Children's negative facial reactions to the neutral and evocative portions of the film (see later) were coded by the same two coders who coded mothers' facial reactions (the reliability coder coded 33 subjects). For each 15$\mathrm{s}$ period of the neutral and evocative periods, children's distress and concerned attention facial expressions were coded with the same criteria and the same 5-point scale used in coding the mothers' facial reactions. Children's sad facial expressions also were coded, but they occurred infrequently $(M=1.44, S D=0.86)$ and were correlated with concerned attention facial expressions, $r(100)=.45, p<.001$. Consequently, sad facial expressions were combined with concerned attention. Composite indexes for each expression were computed by summing the average ratings for each period and dividing each by the number of 15-s periods coded (separately for neutral and evocative sections). Because of equipment problems, facial data were lost for 2 children.

For analysis of children's distress and concerned attention facial expressions, difference scores were used. To control for individual differences in facial expressions in relatively neutral contexts, we computed difference scores by subtracting the ratings for the neutral period from the ratings for the evocative period (Rogosa \& Willett, 1983). Pearson correlations for children's facial distress and concerned attention were .79 and .83 ( $p$ s $<.0001)$, respectively, and kappa coefficients computed on the basis of presence versus absence of a facial expression were .72 and .74 , respectively.

Physiological data. Both HR and SC were recorded on a Marantz PMD 340 stereo audiotape recorder. HR was sampled and recorded every $10 \mathrm{~ms}$, and SC was sampled and recorded every 100 ms. Following the specifications detailed by Fowles et al. (1981), we collected the physiological data using a custom-built two-channel amplifier. Analog signals were digitized before being recorded on the audiotape. Subsequently, the digitized physiological data recorded on audiotapes were entered into a computer and converted using software (see later).

To analyze children's responses to the film, we took physiological data from the most evocative portion of the film. The most evocative portion of the film was determined a priori by three psychologists. The evocative portion of the film consisted of a 35-s period in which the children in the film were seen bandaged in their hospital beds and heard moaning and complaining about their injuries and having nothing to do to pass the time. To obtain a measure of SC reactivity during baseline, neutral conditions, we also obtained measures of SC during the 22-s period at the beginning of the film in which the announcer was introducing the purpose of the film. Because of equipment problems, physiological data were lost for 2 subjects.

For HR, software was used to detect each $\mathrm{R}$ wave and the R-R intervals were calculated and stored in milliseconds. These HR samples were used to compute mean HR per $1 / 2$-s period (using weighted averages). When there was artifact in HR data due to movement or talking (as determined by inspection of the paper record of the raw HR data), the average of the codable HR beats immediately before and after the artifact was used in place of the uncodable data points.

We then computed linear trend analyses for children's HR during the evocative period of the film. We also examined slopes representing linear change in children's HR during the critical period of the film, plus the $2 \mathrm{~s}$ before, by calculating, for each subject, the correlation between mean HR during the consecutive $1 / 2$-s periods and the time period of the HR (numbered from 1 to $k$, with $k$ being the number of time periods). This computation is comparable to computing the beta for the linear trend using individualized multiple regression equations (see Knight \& Dubro, 1984). For both types of analysis, there were no significant findings; thus, we do not discuss them further.

We ran the SC data through a software program that computed phasic responses (using derivatives). Phasic responses included all $\mathrm{SC}$ responses that rose 0.10 micromhos or more, although responses of 2.5 micromhos or larger were assumed to be artifact and were

${ }^{2}$ Children's facial expressions during the storytelling interactions also were coded in the same way that we coded mothers' expressions. A repeated measures analysis of covariance (covarying story order) revealed that children expressed significantly more negative than positive facial affect during the storytelling interactions $(M \mathrm{~s}=1.59$ and $1.20, S D \mathrm{~s}=0.33$ and 0.21 , respectively $), F(1,97)=$ $128.43, p<.000 \mathrm{I}$. These data provide evidence that the content of the stories was relatively distressing. In addition, maternal and child positive and negative facial expressiveness were significantly correlated, $r \mathrm{~s}(100)=.50$ and $.62, p \mathrm{~s}<.0001$, respectively. Because these indexes were correlated, we present only the data for maternal facial expressiveness. Nonetheless, these findings suggest that maternal expressiveness and style of telling the stories were related to children's reactions during the storytelling interactions and that children's facial reactions were consistent with those of the mother (we acknowledge that these could be sequential, bidirectional effects). 
deleted (see Dawson, Schell, \& Fillion, 1990). Moreover, any phasic response that occurred within $3 \mathrm{~s}$ after a child displayed a large, gross body movement was considered artifact and was deleted. Large movements were coded off of the videotapes, and the interrater agreement of the codings of movements for 35 children was $100 \%$. Editing of SC due to large movements occurred for only 7 children, and the average number of phasic responses deleted for these 7 children was 1.43 .

The software program converted the number of SC responses into rate per minute by dividing the number of SC responses by the number of minutes, and it also computed the mean amplitude across the individual's phasic responses. We then created a composite SC score that consisted of the sum of the standardized number of phasic responses per minute and the standardized mean amplitude of these $\mathrm{SC}$ phasic responses. These SC indexes were significantly correlated, $r(100)=.44, p<.001$. Composite SC scores were computed separately for the evocative and neutral portions of the film.

Children's helping behavior. The number of crayons sorted and the amount of time children sorted were highly correlated, $r(100)=$ $.88, p<.0001$. Thus, a composite helping index was created by standardizing each index and then summing them. Because of experimenter error, helping data were lost for 1 subject.

\section{Results}

\section{Descriptive Analyses}

Maternal storytelling indexes. The average amount of time mothers spent telling both stories was $562.97 \mathrm{~s}(S D=$ 291.41 ; range $=183$ to $1,755 \mathrm{~s})$. A $2(\operatorname{sex}) \times 2($ grade $)$ analysis of covariance (covarying order of stories) failed to reveal any significant age or sex differences in the length of time mothers spent telling the stories to their children.

We next examined whether there were differences in mothers' storytelling indexes as a function of the age and sex of their children by computing a multivariate analysis of covariance (covarying order of stories). To reduce the number of variables in the analyses, we created composite scores for the maternal variables. Because maternal warmth and attentional directiveness were significantly, positively related, partial $r(99)=.33, p<.001$ (controlling for story order), a maternal responsiveness composite was created by taking the mean of the maternal warmth and attentional directiveness storytelling indexes. Moreover, the combination of maternal warmth and mothers' efforts to draw children's attention to relevant moral and prosocial content would conceptually and empirically be expected to foster sympathy and prosocial behavior (e.g., Baumrind, 1973; Hoffman, 1982).

A maternal facial expressiveness composite also was created by subtracting the mean for maternal negative expressiveness from the mean for maternal positive expressiveness. This maternal expressiveness composite represented relative positive expressiveness with higher scores reflecting relatively more positive facial expressions. ${ }^{3}$

The multivariate effects for grade and sex were both significant, $F_{\mathrm{s}}(2,96)=15.69$ and $6.62, p \mathrm{~s}<.0001$ and .002 , respectively. Univariate analyses indicated that mothers of younger children were significantly more responsive to their children and evidenced greater levels of positive versus negative facial expressions than did mothers of older children, $F \mathrm{~s}(1,97)=7.93$ and $28.28, p \mathrm{~s}<.0$ land .0001 , respectively. Table 1 presents the means and standard deviations for the various indexes broken down by grade. In addition, mothers were significantly more responsive toward their daughters than to- ward their sons $(M \mathrm{~s}=4.95$ and $4.49, S D \mathrm{~s}=0.85$ and 0.73 , respectively), $F(1,97)=11.07, p<.001$.

Maternal reports of children's emotional reactivity. For mothers' reports of children's emotional reactivity, only the main effect for grade was significant, $F(1,98)=6.48, p<$ .013. Mothers perceived kindergartners to be more emotionally reactive than second graders when the children were exposed to others' negative conditions (see Table 1).

Child film and helping indexes. Similar $2(\mathrm{sex}) \times 2$ (grade) analyses of variance (ANOVAs) were computed to examine age and sex effects for children's reactions to the film and their helping behavior. In the analyses of SC, neutral SC was covaried to control for individual differences in general reactivity.

For children's verbal reports of sympathetic reactions to the stimulus tape., only the Sex $\times$ Grade interaction was significant, $F(1,99)=7.87, p<.006$. According to simple effects analyses computed separately by sex, older girls were more likely to report feeling sympathetic than were younger girls $(M \mathrm{~s}=3.56$ and $2.92, S D \mathrm{~s}=0.98$ and 0.83 , respectively), $F(1,49)=6.48, p<.02$, whereas older and younger boys were more comparable $(M \mathrm{~s}=3.35$ and $3.22, S D \mathrm{~s}=1.33$ and 1.38 , respectively). In addition, boys were significantly more likely than girls to evidence facial distress, $F(1,97)=3.94, p<$ $.05(M \mathrm{~s}=0.66$ and $0.12, S D \mathrm{~s}=1.07$ and 0.90 , respectively). Boys also evidenced significantly higher levels of SC reactivity than did girls $(M \mathrm{~s}=0.11$ and -0.17 , respectively), $F(1,97)$ $=2.57, p<.04$.

According to a final ANOVA, only a significant main effect for grade was found for children's helping behavior, $F(1,98)=17.24, p<.0001$. Second-grade children were significantly more likely to help than were kindergartners (see Table 1).

\section{Interrelations Between Maternal and Child Indexes}

Because of the significant differences found for grade and sex, we analyzed the interrelations among the various study indexes separately by both grade and sex. For the analyses computed by sex, the number of significant correlations was close to chance levels (only 5 of the 64 correlations were found to be significant), and the patterns were similar for boys and girls. Thus, we discuss only the interrelations computed separately by grade (there were 19 significant relations when computed by grade; see Table 2), and our discussion focuses on the patterns found for these relations. In these analyses, we partialed sex of child for all analyses and order of story for all analyses involving maternal storytelling indexes. In addition, we partialed neutral SC for all analyses involving SC during the evocative portion of the film.

Maternal storytelling indexes and their perceptions of children's emotional reactivity. Although the maternal storytelling indexes (responsiveness and positive vs. negative facial expressiveness) were not found to be significantly correlated with each other, they were both significantly related to mothers' perceptions of their children's emotional reactivity (see Table 2).

\footnotetext{
${ }^{3}$ Maternal facial positive and negative expressiveness were not significantly correlated, partial $r \mathrm{~s}(45)$ and (49) for younger and older children were .19 and $-.09, p \mathrm{~s}>.2$, respectively (controlling for sex and story order).
} 
Table 1

Means and Standard Deviations: By Grade

\begin{tabular}{|c|c|c|c|c|c|c|}
\hline \multirow[b]{2}{*}{ Measure } & \multicolumn{3}{|c|}{ Kindergartners } & \multicolumn{3}{|c|}{ 2nd graders } \\
\hline & $n$ & $M$ & $S D$ & $n$ & $M$ & $S D$ \\
\hline \multicolumn{7}{|l|}{ Maternal storytelling indexes } \\
\hline Responsiveness & 49 & $4.91_{1}$ & .83 & 53 & $4.53_{1}$ & .77 \\
\hline Facial expressiveness $^{a}$ & 49 & $.19_{2}$ & .37 & 54 & $-.21_{2}$ & .38 \\
\hline Child emotional reactivity & 48 & $3.93_{3}$ & 1.79 & 54 & $3.10_{3}$ & 1.38 \\
\hline \multicolumn{7}{|l|}{ Child film-viewing indexes } \\
\hline Verbal sympathy & 49 & 3.23 & .97 & 54 & 3.37 & .93 \\
\hline Facial concerned attention ${ }^{\mathrm{b}}$ & 49 & .29 & .37 & 52 & .34 & .36 \\
\hline Facial distress $^{\mathrm{b}}$ & 49 & .40 & 1.25 & 52 & .39 & 1.49 \\
\hline \multicolumn{7}{|l|}{ Skin conductance } \\
\hline Neutral $^{\mathrm{c}}$ & 49 & .13 & .87 & 53 & -.12 & .75 \\
\hline Evocative $^{c}$ & 49 & -.14 & .95 & 53 & -.39 & .91 \\
\hline Child helpfulness $^{d}$ & 48 & $-.42_{4}$ & .95 & 54 & $.69_{4}$ & 1.72 \\
\hline
\end{tabular}

Note. Means with same numeric subscript are significantly different.

${ }^{\text {a }}$ Composite of maternal positive facial expressiveness - maternal negative facial expressiveness. ${ }^{\mathrm{b}}$ Difference score. ${ }^{\mathrm{c}}$ Standarized composite $=$ standardized number of phasics + standardized mean amplitude. ${ }^{\mathrm{d}}$ Standardized composite $=$ standardized amount of time helped + standardized number of crayons packaged.

Specifically, mothers' positive versus negative facial expressiveness during the stories was positively correlated with their perceptions of younger children's emotional reactivity, whereas maternal responsiveness was inversely related to their perceptions of older children's emotional reactivity. Thus, the ways mothers reacted in the storytelling situation varied with their perceptions of their children's tendencies to become emotionally reactive when exposed to others in distress. Moreover, the relations differed for older and younger children.

Maternal storytelling indexes and child film indexes and helpfulness. The partial correlations between maternal storytelling indexes and child film indexes and helpfulness also varied as a function of the grade of the child. For kindergart- ners, mothers' positive versus negative facial expressiveness was positively related to children's helpfulness. Thus, mothers of kindergartners who expressed high rates of positive (compared with negative) facial expressions had children who were relatively likely to help others (see Table 2).

When we examined the relations between maternal positive and negative facial affect separately, the same general trends found in Table 2 resulted. For younger children, maternal positive expressiveness was inversely related to facial distress, partial $r(44)=-.43, p<.003$, and positively related to dispositional reactivity, partial $r(45)=.53, p<.001$. Maternal negative facial expressiveness was inversely related to younger children's helpfulness, partial $r(45)=-.31, p<.05$. No significant relations were found for older children. These

Table 2

Interrelations Among Study Measures: By Grade

\begin{tabular}{|c|c|c|c|c|c|c|c|c|}
\hline Measure & 1 & 2 & 3 & 4 & 5 & 6 & 7 & 8 \\
\hline \multicolumn{9}{|l|}{ Maternal storytelling indexes } \\
\hline 1. Responsiveness & - & .25 & .19 & .12 & .03 & -.11 & -.25 & .11 \\
\hline 3. Child emotional reactivity & $-.33^{*}$ & -.02 & - & $.34^{*}$ & -.17 & $-.33^{*}$ & -.25 & $.29^{*}$ \\
\hline \multicolumn{9}{|l|}{ Child film-viewing indexes } \\
\hline 4. Verbal sympathy & .05 & .06 & $-.28 *$ & - & $-.33^{*}$ & -.15 & .03 & .15 \\
\hline 5. Facial concerned attention ${ }^{b}$ & $.28^{*}$ & .01 & $-.29 *$ & .13 & - & .06 & .01 & -.21 \\
\hline 8. Child helpfulness ${ }^{\mathrm{d}}$ & $.28^{*}$ & -.04 & $-.36^{* *}$ & .12 & $.30^{*}$ & -.19 & $-.38 * *$ & - \\
\hline
\end{tabular}

Note. Partial correlations for kindergartners are presented above the diagonal, and second-graders' correlations coefficients are presented below the diagonal. For all analyses, sex of child was partialed. For those analyses involving maternal storytelling indexes, order of stories also was partialed, and for those analyses involving skin conductance (SC), neutral SC also was partialed. Degrees of freedom for younger children ranged from 44 to 45; degrees of freedom for older children ranged from 47 to 51 .

${ }^{\mathrm{a}}$ Composite of maternal positive facial expressiveness - maternal negative facial expressiveness. $\quad{ }^{\mathrm{b}}$ Difference score. ${ }^{\mathrm{c}}$ Standardized composite $=$ standardized number of phasics + standardized mean amplitude. ${ }^{\mathrm{d}}$ Standardized composite $=$ standardized amount of time helped + standardized number of crayons packaged.

${ }^{*} p<.05 .^{* *} p<.01{ }^{* * *} p<.005{ }^{* * * *} p<.0001$. 
findings suggest that mothers may have been trying to induce positive moods and avoid inducing negative moods in their younger children.

For second-grade children, maternal responsiveness was positively related to both facial concerned attention and helpfulness and inversely related to children's facial distress and $\mathrm{SC}$ reactivity (see Table 2 ). Thus, sympathetic and helpful responding for second graders was related to the degree to which mothers were responsive to their children during the storytelling context. Conversely, children's distress responses were related to relatively low levels of maternal responsiveness.

Relation of perceived emotional reactivity to children's film indexes and helpfulness. Mothers' perceptions of children's vicarious emotional reactivity also were related to how their children responded to the film and the helping task (see Table 2). For kindergartners, mothers' perceptions of children's emotional reactivity were positively related to their helpfulness and verbal reports of sympathy and inversely related to facial distress. For older children, mothers' perceptions of emotional reactivity were inversely related to reports of sympathy, facial concerned attention, and helpfulness. Thus, for younger children, their emotional reactivity in empathy-inducing contexts (as reported by mothers) appeared to reflect sympathy; however, this was not the case for older children.

\section{Relations Among Child Film Indexes and Their Helpfulness}

Next, we examined the interrelations among markers of children's personal distress, sympathy, and helpfulness. Consistent with the assertion that SC is an internal marker of personal distress, SC was positively related to facial distress and inversely related to helping for both older and younger children (see Table 2). Moreover, for older children, only facial concerned attention was positively related with children's helpfulness. Finally, kindergartners' verbal reports of sympathy were unexpectedly inversely related to their facial expressions of concerned attention.

\section{Relation of SC to Children 's Helpfulness}

Because of the important role that regulation of arousal is thought to play in determining children's prosocial behavior (Eisenberg \& Fabes, 1992; Hoffman, 1982), we also computed hierarchical regression analyses (separately by grade) to examine the relative contribution of children's SC reactivity (our internal marker of personal distress) to their helpfulness. First, we entered the control variables of sex, neutral SC, and story order. Next, we entered the maternal storytelling index that predicted helpfulness (facial expressiveness for young children and maternal directiveness for older children) and perceived reactivity indexes (as a group), and, finally, we entered SC reactivity into the equation. Importantly, for both grades, SC reactivity explained a significant amount of the variance above and beyond that explained by all other predictors, $F(1,42)$ and $F(1,48)$ for $R_{\text {change }}^{2}=7.32$ and $6.00, p \mathrm{~s}<$ .005 and .02 , for younger and older children, respectively.

\section{Discussion}

There are several findings in the present study that advance our understanding of the relations among children's vi- carious, emotional responding and prosocial behavior, mothers' perceptions of their children's emotional reactivity, and mothers' interactions and responses when telling emotion-laden stories to their children. First, the ways that mothers told affect-laden stories to their children varied with the age of their children. Mothers of kindergarten-age children were rated as significantly more responsive to their children than were mothers of second graders. In addition, mothers of kindergartners exhibited relatively more positive facial expressions while telling stories than did mothers of second graders. Thus, mothers tended to be more interactive, comforting, and affectionate when telling stories to younger than older children. Such findings suggest that parents of younger children may be more concerned about how their children are going to react to stories of others in distress than parents of older children and thus are more likely to act to "buffer" the impact of these stories on their children. In fact, the finding that mothers of younger children rated their children as more emotionally reactive when exposed to others in distress than did mothers of second graders supports the contention that mothers may have responded to differences in the ways that older and younger children react to others in distress.

We also found gender differences in the ways mothers interacted with their children when telling stories. Mothers of girls were rated as more responsive than were mothers of boys. In contrast to the findings for age, there were no significant gender differences in mothers' perceptions of sons' and daughters' emotional reactivity. Thus, it appears that mothers responded in a manner consistent with the stereotype that girls should be reared to be more socially sensitive, expressive, and prosocial than boys (e.g., Parsons \& Bales, 1955) rather than on the basis of sex-typed beliefs about differences in girls' and boys' levels of emotional reactivity.

Mothers' behaviors in the story context also varied according to their perceptions of their children's emotional reactivity, and these perceptions appeared to be influenced by the age of their children. As noted previously, kindergarteners were perceived by mothers as more emotionally reactive to others' distress than were second graders. In addition, for kindergarten children, mothers' perceptions of children's emotional reactivity were positively related to their relative use of positive versus negative facial expressiveness while telling the stories. It appears that mothers of the young children in our study attempted to minimize children's negative responses to the stories by trying to induce a positive mood in their children (or avoid inducing a negative one). This was especially likely for young children whose mothers believed that their children were prone to become emotionally aroused when exposed to others in distress. Thus, mothers' actions appeared to be influenced by their perceptions of their children's vulnerability to become dysregulated as a consequence of exposure to others' negative affect.

In contrast, mothers' beliefs about the emotional reactivity of second graders were inversely related to their responsiveness while telling the stories. Mothers who perceived their older children to be emotionally reactive tended to be less involved and warm in the storytelling context than were mothers who believed that their second-grade children were more emotionally controlled. It appears that mothers who perceive their older children to be emotionally reactive may "back off" from socialization efforts that actively 
involve their children in a particular distressing experience. Such findings are similar to those of Maccoby et al. (1984), who found that mothers who perceived their sons to be difficult became less actively engaged than mothers who did not hold these perceptions.

Our findings suggest that mothers' definitions of emotional reactivity may vary with the age of the child. Interestingly, mothers' perceptions of children's emotional reactivity in situations involving others' distress were positively related to markers of sympathetic and prosocial responding for kindergartners but were inversely related to similar indexes for older children. For younger children, mothers may find sympathetic responses particularly salient when their child is exposed to others in distress because they are trying to teach their children appropriate responses in these situations and thus are particularly attentive to their expression. In contrast, mothers of older children, because of their expectations that their children should already know and be sufficiently regulated to enact the appropriate emotional and prosocial responses when others are distressed, may find non-sympathy-related responses (although not personal distress as measured in our study) more salient because they deviate from their expectations. At older ages, children's emotional reactivity may be more likely to be associated generally with dysregulation than is the case for younger children with less experience in managing their own and others' emotions. Perhaps these older, reactive children are prone to angry, aggressive, or avoidant responses when distressed or aroused, and thus are viewed by mothers as temperamentally difficult. As such, mothers of older children may back away from efforts to influence these children. Given that children with easy temperamental styles appear to be more responsive to caregiving efforts than are difficult children (Wachs \& Gandour, 1981), mothers of older children who are perceived as emotionally reactive or difficult may have an experiential basis for expecting their socializing efforts to be relatively less effective. Caution, however, must be used when considering the present findings because of possible order effects due to the fact that the maternal perception index was always obtained after the stories were told.

Consistent with our conceptual model and predictions, the ways mothers told the stories also related to children's vicarious emotional responding to the film and their subsequent prosocial behavior. For younger children, mothers' relative use of positive facial expressions was positively correlated with children's helpfulness. This finding supports the conclusion that mothers who try to buffer or counteract children's negative reactions in distressing contexts have children who are more prosocial than those mothers who do not (Bryant, 1987), and it adds to the prior literature by suggesting that maternal expressions of positive affect may be particularly important for the development of sympathy in younger children. Of course, the degree to which mothers feel they need to buffer their children's reactions may be due, in part, to the child's emotional reactivity (see previous paragraph). Caution, however, needs to be exercised in regard to the findings for maternal expressiveness, because mothers were told in advance that they would be videotaped and any difference found may have been influenced by this awareness.

In contrast, second graders' emotional and prosocial responses were predicted by maternal responsiveness rather than mothers' affective expressiveness. Maternal responsiveness was related to lower levels of distress-related responses and to increased sympathetic and prosocial responding. Of course. children who are socially competent may elicit differential responses in their mothers compared with children who are less competent.. Clearly, there is a need to conduct longitudinal research to determine how mothers' perceptions and expectations regarding children's vicarious emotional responsiveness change over time and how maternal behaviors may relate to these changes. Moreover, caution should be used in generalizing the findings of this study, as there was not a "control" story included that could be used as a comparison to judge whether mothers' storytelling behaviors were unique to stories involving distressing content.

The results of this study also supported the contention that $\mathrm{SC}$ can be used as an internal marker of personal distress. For both older and younger children, SC was positively related to facial distress and, as predicted, inversely related to helpfulness. Thus, similar to the findings of others (e.g., Fabes et al., 1993), the degree to which children become dysregulated predicted prosocial behavior. Interestingly, we found that $\mathrm{SC}$ explained a significant amount of the variance related to helpfulness above and beyond maternal perceptions and interactions during the storytelling contexts. It appears that children's physiological reactivity during the film was a significant predictor of children's helpfulness even when the other predictors were controlled. Such findings support the notion that children's ability to regulate their physiological arousal when exposed to others in distress may be an important determinant of children's prosocial responsiveness and may be due, in part, to temperamental factors that are not easily affected by parental socialization efforts (at least those efforts measured in the present study).

Contrary to previous findings (e.g., Eisenberg \& Fabes, 1990; Eisenberg et al., 1989), we did not find relations between children's HR responses and their vicarious emotional responding or prosocial behavior. One reason for this may have been because of the particular stimulus film used in the present study. Initially, this film was produced for use with preschool-age children and involved a simplified description of the accident and of the protagonists' expressions of pain and boredom (see Eisenberg et al., 1990). As such, the film may not have been as evocative or involving as were the stimuli used in much of the past research. Because HR responses may be dependent on the degree to which the children are oriented to, and involved in, the stimulus film, the simplified .presentation may have minimized individual differences in children's HR responses to the film.

In summary, the findings of this study support the notion that mothers' perceptions of their children are related to the ways they interact with them. The findings also suggest that this relation is influenced by the behaviors, characteristics, and age of the child. Moreover, it was found that individual differences in children's physiological reactivity predicted their helpfulness above and beyond the contribution of maternal treatment. Thus, future researchers should focus on both the individual and socialization influences, as well as the interaction of these influences, to more clearly explicate the processes involved in children's reactions to others in distress. 


\section{References}

Barnett, M. A. (1987). Empathy and related responses in children. In N. Eisenberg \& J. Strayer (Eds.), Empathy and its development (pp. 46-102). Cambridge, England: Cambridge University Press.

Barnett, M. A., King, L. M., Howard, J. A., \& Dino, G. A. (1980). Empathy in young children: Relation to parents' empathy, affection, and emphasis on the feelings of others. Developmental Psychology, 16, 243-244.

Batson, C. D. (1987). Prosocial motivation: Is it ever truly altruistic? In L. Berkowitz (Ed.), Advances in experimental social psychology (Vol. 20, pp. 65-122). San Diego, CA: Academic Press.

Batson, C. D., Fultz, J., \& Schoenrade, P. A. (1987). Distress and empathy: Two qualitatively distinct vicarious emotions with different motivational consequences. Journal of Personality, 55, 1940 .

Baumrind, D. (1973). The development of instrumental competence through socialization. In A. D. Pick (Ed.), Minnesota symposium on child psychology (Vol. 7, pp. 3-46). Minneapolis: University of Minnesota Press.

Bell, R. Q. (1968). A reinterpretation of the direction of effects in studies of socialization. Psychological Review, 75, 81-95.

Block, J. H. (1979). Another look at sex differentiation in the socialization behaviors of mothers and fathers. In J. Sherman \& F. L. Denmark (Eds.), Psychology of women: Future of research (pp. 29-87). New York: Psychological Dimensions.

Brody, L. R. (1985). Gender differences in emotional development: A review of theories and research. Journal of Personality, 53, 102-149.

Bryant, B. K. (1987). Mental health, temperament, family, and friends: Perspectives on children's empathy and social perspective taking. In N. Eisenberg \& J. Strayer (Eds.), Empathy and its development (pp. 245-270). Cambridge, England: Cambridge University Press.

Bugental, D. B., \& Shennum, W. A. (1984). "Difficult" children as elicitors and targets of adult communication patterns: An attributional-behavioral transactional analysis. Monographs of the Society for Research in Child Development. 49 (1, Serial No. 205).

Cacioppo, J. T., \& Sandman, C. A. (1978). Physiological differentiation of sensory and cognitive tasks as a function of warning processing demands and reported unpleasantness. Biological Psychology, 6, 181-192.

Craig, K. D. (1968). Physiological arousal as a direct function of imagined, vicarious, and direct stress experiences. Journal of Abnormal Psychology, 73, 513-520.

Craig, K. D., \& Lowery, H. J. (1969). Heart-rate components of conditioned vicarious autonomic responses. Journal of Personality and Social Psychology, 11, 381-387.

Crockenberg, S. B. (1986). Are temperamental differences in babies associated with predictable differences in care-giving? In J. V. Lerner \& R. M. Lerner (Eds.), Temperament and social interactions in infants and children (pp. 53-74). San Francisco: JosseyBass.

Dawson, M. E., Schell, A. M., \& Fillion, D. L. (1990). The electrodermal system. In J. T. Cacioppo \& L. T. Tassinary (Eds.), Principles of psychophysiology (pp. 295-324). Cambridge, England: Cambridge University Press.
Egeland, B., \& Sroufe, L. A. (1981). Attachment and early maltreatment. Child Development, 52, 44-52.

Eisenberg, N. (1992). The caring child. Cambridge, MA: Harvard University Press.

Eisenberg, N., \& Fabes, R. A. (1990). Empathy: Conceptualization, measurement, and relation to prosocial behavior. Motivation and Emotion, 14, 131-149.

Eisenberg, N., \& Fabes, R. A. (1992). Emotion, regulation, and the development of social competence. In M. S. Clark (Ed.), Emotion and social behavior (Vol. 14, pp. 119-150). Newbury Park, CA: Sage.

Eisenberg, N., \& Fabes, R. A. (in press). Socialization of vicarious emotional responsiveness in children. Merrill-Palmer Quarterly.

Eisenberg, N., Fabes, R. A., Bustamante, D., Mathy, R., Miller, P., \& Lindholm, E. (1988). Differentiation of vicariously induced emotional reactions in children. Developmental Psychology, 24, 237-246.

Eisenberg, N., Fabes, R. A., Carlo, G., Troyer, D., Speer, A. L., Karbon, M., \& Switzer, G. (1992). The relations of maternal practices and characteristics to children's vicarious emotional responsiveness. Child Development, 63, 582-603.

Eisenberg, N., Fabes, R. A., Miller, P. A., Fultz, J., Mathy, R. M., Shell, R., \& Reno, R. R. (1989). The relations of sympathy and personal distress to prosocial behavior: A multimethod study. Journal of Personality and Social Psychology, 57, 55-66.

Eisenberg, N., Fabes, R. A., Miller, P., Shell, R., \& Plumlee, T. (1990). Sympathy and children's spontaneous prosocial behavior. Merrill Palmer Quarterly, 26, 507-529.

Eisenberg, N., Fabes, R. A., Murphy, B., Karbon, M., Maszk, P., Smith, M., O'Boyle, C., \& Suh, K. (1993). Temperament and vicarious emotional responding. Manuscript submitted for publication.

Eisenberg, N., Fabes, R. A., Schaller, M., Carlo, G., \& Miller, P. (1991). The relations of parental characteristics and practices to children's vicarious emotional responding. Child Development, 62, 1393-1408.

Eisenberg, N., \& Strayer, J. (1987). Critical issues in the study of empathy. In N. Eisenberg \& J. Strayer (Eds.), Empathy and its development (pp. 3-16). Cambridge, England: Cambridge University Press.

Ekman, P., \& Friesen, W. V. (1975). Unmasking the face. Palo Alto, CA: Consulting Psychologists Press.

Ekman, P., \& Friesen, W. V. (1978). The facial action coding system. Palo Alto, CA: Consulting Psychologists Press.

Fabes, R. A., Eisenberg, N., \& Eisenbud, L. (1993). Behavioral and physiological correlates of children's reactions to others in distress. Developmental Psychology, 29, 655-663.

Fabes, R. A., Eisenberg, N., \& Miller, P. (1990). Maternal correlates of children's vicarious emotional responsiveness. Developmental Psychology, 26, 639-648.

Fowles, D. C., Christie, M. J., Edelberg, R., Grings, W. W., Lykken, D. T., \& Venables, P. H. (1981). Publication recommendations for electrodermal measurements. Psychophysiology, 18, 232239.

Gianino, A., \& Tronick, E. Z. (1988). The mutual regulation model: The infant's self and interactive regulation and coping and 
defensive capacities. In T. M. Field, P. M. McCabe, \& N. Schneiderman (Eds.), Stress and coping across development (pp. 47-70). Hillsdale, NJ: Erlbaum.

Gottman, J., \& Mettetal, G. (1986). Speculations about social and affective development: Friendship and acquaintanceship through adolescence. In J. Gottman \& J. G. Parker (Eds.), Conversations of friends: Speculations on affective development (pp. 192-240). Cambridge, England: Cambridge University Press.

Halberstadt, A. G. (1986). Family socialization and nonverbal communication styles and skills. Journal of Personality and Social Psychology, 51, 827-836.

Higgins, E. T., \& Parsons, J. E. (1983). Social cognition and the social life of the child: Stages as subcultures. In E. T. Higgins, D. N. Ruble, \& W. W. Hartup (Eds.), Social cognition and social development (pp. 15-62). Cambridge, England: Cambridge University Press.

Hoffman, M. L. (1982). Development of prosocial motivation: Empathy and guilt. In N. Eisenberg (Ed.), The development of prosocial behavior (pp. 218-231). San Diego, CA: Academic Press.

Kestenbaum, R., Farber, E. A., \& Sroufe, L. A. (1989). Individual differences in empathy among preschoolers: Relation to attachment history. In N. Eisenberg (Ed.), New directions in child development (Vol. 44, pp. 51-64). San Francisco: Jossey-Bass.

Knight, G. P., \& Dubro, A. F. (1984). Cooperative, competitive, and individualistic social values: An individualized regression and clustering approach. Journal of Personality and Social Psychology, 46, 98-105.

Koestner, R., Franz, C., \& Weinberger, J. (1990). The family origins of empathic concern: A 26-year longitudinal study. Journal of Personality and Social Psychology, 58, 709- 717.

Kopp, C. B. (1989). Regulation of distress and negative emotions: A developmental view. Developmental Psychology, 25, 343-354.

Maccoby, E., Snow, M. E., \& Jacklin, C. (1984). Children's dispositions and mother-child interaction at 12 and 19 months: A shortterm longitudinal study. Developmental Psychology, 20, 459472.

Parsons, T., \& Bales, R. F. (1955). Family, socialization, and interaction processes. San Diego, CA: Academic Press.

Pulkkinen, L. (1982). Self-control and continuity from childhood to adolescence. In P. B. Baltes \& O. G. Brim (Eds.), Life-span development and behavior (Vol. 4, pp. 63-105). San Diego, CA: Academic Press.
Roberts, W. R., \& Strayer, J. (1987). Parents' responses to the emotional distress of their children: Relations with children's competence. Developmental Psychology, 23, 415-422.

Robinson, J. P. (1981). Television and leisure time: A new scenario. Journal of Communication, 31, 120-130.

Rogosa, D. R., \& Willett, J. B. (1983). Demonstrating the reliability of the difference score in the measurement of change. Journal of Educational Measurement, 20, 335-343.

Rothbart, M. K., Ahadi, S. A., \& Hershey, K. L. (in press). Temperament and social behavior in childhood. Merrill-Palmer Quarterly.

Santostefano, S. (1985). Cognitive control therapy with children and adolescents. Elmsford, NY: Pergamon Press.

Shaver, P., Schwartz, J., Kirson, D., \& O’Connor, C. (1987). Emotion knowledge: Further exploration of a prototype approach. Journal of Personality and Social Psychology, 52, 1061-1086.

Sparks, G. G. (1989). Understanding emotional reactions to a suspenseful movie: The interaction between forewarning and preferred coping style. Communication Monographs, 56, 325-340.

Staub, E. (1989). The roots of evil: The origins of genocide and other group violence. Cambridge, England: Cambridge University Press.

Wachs, T., \& Gandour, M. J. (1981). The relationship of temperament and environment to cognitive development at 6 months. International Journal of Behavioral Development, 6, 135-152.

Wispe, L. (1987). History of the concept of empathy. In N. Eisenberg \& J. Strayer (Eds.), Empathy and its development (pp. 17-37). Cambridge, England: Cambridge University Press.

Wood, J. V., Saltzberg, J. A., \& Goldsamt, L. A. (1990). Does affect induce self-focused attention? Journal of Personality and Social Psychology, 58, 899-908.

Zahn-Waxler, C., Radke-Yarrow, M., \& King, R. A. (1979). Child rearing and children's prosocial initiations towards victims of distress. Child Development, 50, 319-330.

Zahn-Waxler, C., Robinson, J. L., \& Emde, R. N. (1992). The development and heritability of empathy. Developmental Psychology, 28, 1038-1047.

Submitted May 1992; revised June 1993; accepted June 1993. 